\title{
Wheat allergy: diagnosis and management
}

\author{
This article was published in the following Dove Press journal: \\ Journal of Asthma and Allergy \\ 29 January 2016 \\ Number of times this article has been viewed
}

\author{
Antonella Cianferoni \\ Department of Pediatrics, Division \\ of Allergy and Immunology, \\ The Children's Hospital of \\ Philadelphia, PA, USA
}

Correspondence: Antonella Cianferoni Department of Pediatrics, Division of Allergy and Immunology, The Children's Hospital of Philadelphia, 3550 Market Street, Suite 3054, PA 19104-4399, USA Tel +I 2155902549

Fax +I 2155904529

Email cianferonia@email.chop.edu
Abstract: Triticum aestivum (bread wheat) is the most widely grown crop worldwide. In genetically predisposed individuals, wheat can cause specific immune responses. A food allergy to wheat is characterized by $\mathrm{T}$ helper type 2 activation which can result in immunoglobulin $\mathrm{E}$ (IgE) and non-IgE mediated reactions. IgE mediated reactions are immediate, are characterized by the presence of wheat-specific IgE antibodies, and can be life-threatening. Non-IgE mediated reactions are characterized by chronic eosinophilic and lymphocytic infiltration of the gastrointestinal tract. IgE mediated responses to wheat can be related to wheat ingestion (food allergy) or wheat inhalation (respiratory allergy). A food allergy to wheat is more common in children and can be associated with a severe reaction such as anaphylaxis and wheat-dependent, exerciseinduced anaphylaxis. An inhalation induced IgE mediated wheat allergy can cause baker's asthma or rhinitis, which are common occupational diseases in workers who have significant repetitive exposure to wheat flour, such as bakers. Non-IgE mediated food allergy reactions to wheat are mainly eosinophilic esophagitis (EoE) or eosinophilic gastritis (EG), which are both characterized by chronic eosinophilic inflammation. EG is a systemic disease, and is associated with severe inflammation that requires oral steroids to resolve. EoE is a less severe disease, which can lead to complications in feeding intolerance and fibrosis. In both EoE and EG, wheat allergy diagnosis is based on both an elimination diet preceded by a tissue biopsy obtained by esophagogastroduodenoscopy in order to show the effectiveness of the diet. Diagnosis of IgE mediated wheat allergy is based on the medical history, the detection of specific IgE to wheat, and oral food challenges. Currently, the main treatment of a wheat allergy is based on avoidance of wheat altogether. However, in the near future immunotherapy may represent a valid way to treat IgE mediated reactions to wheat.

Keywords: IgE mediated food allergy, non-IgE mediated food allergy, wheat allergy, baker's asthma, wheat dependent exercise induced anaphylaxis, eosinophilic esophagitis, eosinophilic gastritis

\section{Introduction}

Triticum aestivum (bread wheat) is the most widely grown crop worldwide due being easy to grow in different climates and delivering high yields. ${ }^{1}$ Moreover, wheat has a high nutritional value, high palatability, and can be processed into many foods, such as breads, pasta, pizza, bulgur, couscous, and in drinks such as beer. ${ }^{1}$ However, wheat is an increasingly recognized trigger for immune mediated food allergies, both immunoglobulin E (IgE) and non-IgE mediated (Figure 1). ${ }^{1}$

These reactions are typically characterized by a T helper type 2 (Th2) lymphocytic inflammation with predominant Th2 cytokines expression (ie, interleukin (IL)-4, IL-13, and IL-5). Th2 inflammation can lead B cells to produce IgE antibodies specific to 


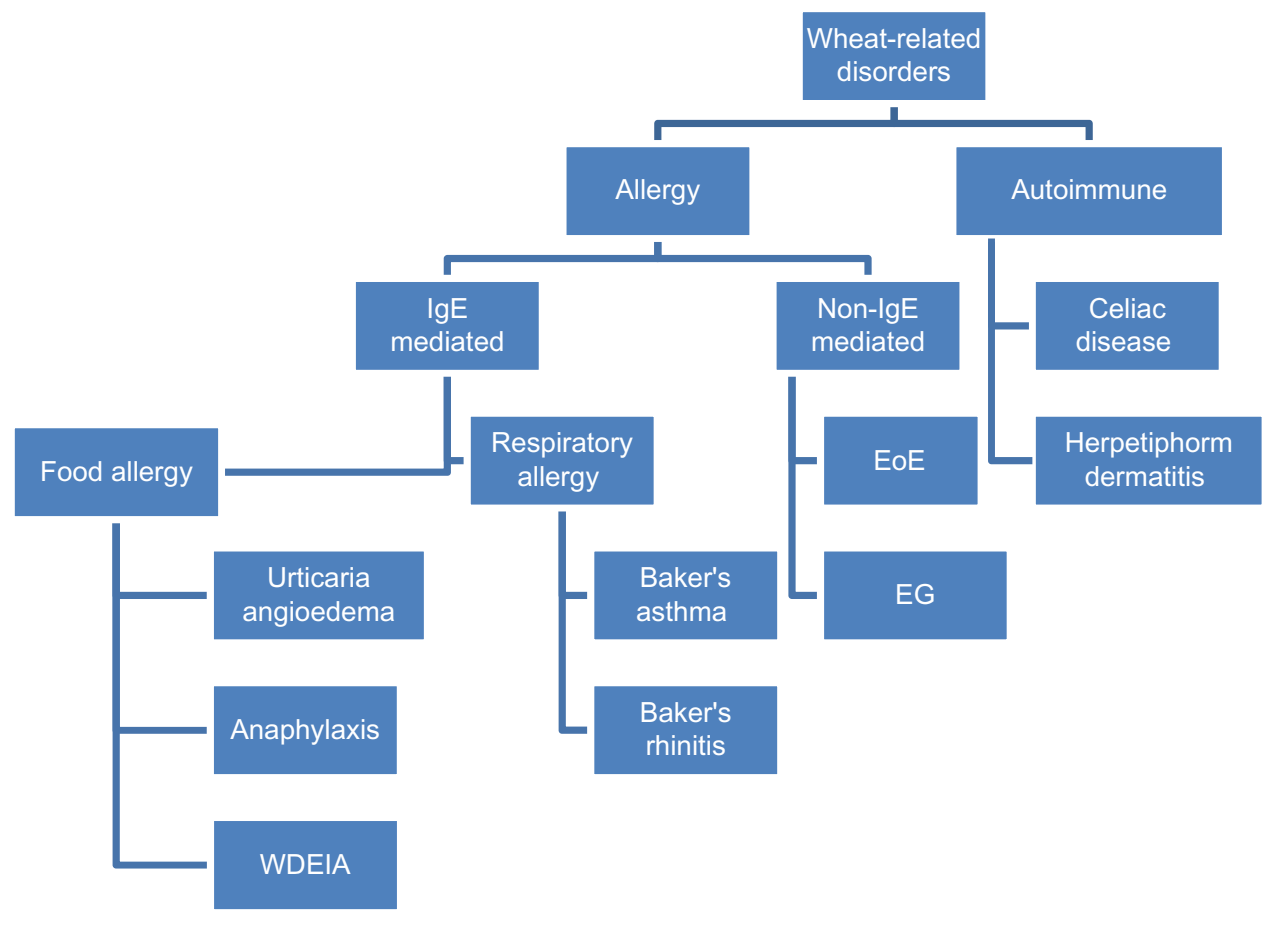

Figure I Diagram of immune reaction to wheat.

Abbreviations: EG, eosinophilic gastritis; EoE, eosinophilic esophagitis; IgE, immunoglobulin E; WDEIA, wheat-dependent, exercise-induced anaphylaxis.

certain foods (in IgE mediated food allergy), or can lead to a chronic cellular inflammation often characterized by the presence of $\mathrm{T}$ cell and eosinophils, which is a much less understood pathogenetic mechanism (non-IgE mediated food allergy). ${ }^{2}$ This paper will review the literature on epidemiology, pathogenesis, diagnosis, and management on the most common IgE mediated and non-IgE mediated food allergies triggered by wheat.

Ingestion of wheat can cause non-Th2 inflammatory reactions, such as celiac disease in genetically susceptible individuals (ie, carriers of HLA class II DQ2 or DQ8). ${ }^{1}$ In celiac disease gluten proteins from wheat, rye, and barely elicit a $T$ helper type 1 mediated inflammation, which is similar to the one observed in autoimmune diseases. ${ }^{1}$ Current reviews focus only on food allergy reactions to wheat (Figure 1).

\section{IgE-mediated reactions to wheat Epidemiology}

IgE mediated reactions to wheat are well-known and can be due to either ingestion (food allergy) or inhalation (respiratory allergy) (Figure 1).

A food allergy to wheat manifests with a variety of symptoms that include urticaria/angioedema, asthma, allergic rhinitis, abdominal pain, vomiting, acute exacerbation of atopic dermatitis, and exercise-induced anaphylaxis (EIA). ${ }^{3-5}$ The prevalence of IgE mediated food allergy to wheat confirmed by the food challenge is unknown. Data from positive skin prick tests (SPTs) indicates that up to $3 \%$ of the general American pediatric population have a food allergy to wheat, however, it is more likely estimated to be $0.2 \%$ to $1 \% \cdot{ }^{6-11}$ Children have a higher prevalence of food allergy to wheat compared to adults, especially if wheat was introduced after 6 months of age. ${ }^{7}$ The increased prevalence in children compared to adults can be explained by the fact that most patients outgrow their allergy by the age of 16 years. ${ }^{12}$ Keet et al reported that children tend to outgrow wheat allergies with a resolution rate of $65 \%$ by the age of 12 years. ${ }^{12}$ Although it was reported that higher wheat IgE levels were associated with poorer outcomes, children outgrew their wheat allergy with even the highest levels of wheat $\operatorname{IgE} .^{12}$

Wheat has been increasingly reported to be a risk factor for severe anaphylactic as well as for wheat-dependent, exercise-induced anaphylaxis (WDEIA). ${ }^{3,13-15}$ In a population of children allergic to wheat, more than $50 \%$ had experienced anaphylaxis upon wheat ingestion. ${ }^{3}$ Cianferoni et al also reported that wheat could be involved in food-induced near-fatal or severe anaphylaxis in a study of 1,000 patients with a food allergy. ${ }^{3}$

EIA is a particular type of anaphylaxis that occurs while performing intense exercise, and may occur independently of food ingestion (EIA) or in close relationship with the timing of food ingestion (food dependent EIA [FDEIA], 30\%-50\% 
of EIA). ${ }^{16}$ FDEIA is diagnosed when anaphylactic episodes occur after the ingestion of a food that is otherwise well tolerated preceding intense exercise (up to 6 hours later, but usually within 1-3 hours). ${ }^{4}$ Wheat is now recognized as an important and frequent cause of FDEIA, also called WDEIA. WDEIA can manifest at any age, with teens and adults without any prior history of food allergy to be the most affected. ${ }^{16}$

Respiratory IgE mediated allergies to wheat are represented by baker's asthma or rhinitis, and are often associated as occupational diseases. The incidence of bakers' asthma range from $1 \%-10 \%$ of bakers, and the incidence of rhinitis range from $18 \%-29 \% .{ }^{17,18}$ Respiratory IgE mediated allergies tend to be more frequent in atopic subjects who are exposed to high levels of wheat allergens for several hours per day. The majority of affected individuals did not suffer from asthma before developing the occupational disease. ${ }^{18}$

\section{Pathogenesis}

Classic IgE mediated reactions to a food allergen are immediate, reproducible, and food-specific IgE can be demonstrated. The clinical manifestations are due to the mediator release (ie, histamine, platelets activator factor, and leukotrienes) from mast cells and basophils. ${ }^{19,20}$ When a specific allergen engages two specific IgE antibodies bound to their high-affinity $\operatorname{IgE}$ receptor (FceRI) it induces the cross link of the FceRI and causes the activation of mast cell and basophils. IgE production against a certain allergen, including wheat, is believed to be due to a breach in oral tolerance and a consequence of Th2-biased immune dysregulation that induces sensitization and B-cell specific allergen IgE production. ${ }^{21-25}$ Both individual genetic characteristics and environmental factors play a role in favoring such immune dysregulation. ${ }^{22,26,27}$ Moreover, the intrinsic properties of food allergens also contribute to whether the allergen favors allergic immune responses. Indeed the "major" food allergens are 10 to 70 $\mathrm{kDa}$ water-soluble glycoproteins and are relatively stable to heat, acid, and proteases degradation. ${ }^{28}$

The protein content in wheat represents $10 \%-15 \%$ of the wheat grain dry weight. Protein can be classified into two fractions based on their solubility in salt: 1) the salt soluble fraction includes albumins and globulin and represents $15 \%-20 \%$ of total proteins; this fraction includes amylase/ trypsin inhibitor subunit as well as other proteins such as lipid transfer protiens, ${ }^{29}$ and 2) the salt insoluble fraction includes gliadin and gluten and represents approximately $80 \%$ of wheat protein content, with gluten comprising about half of such fraction. $5,30,31$
The major allergens of wheat are listed in Table 1. $\alpha$-Amylase/trypsin inhibitor binds to specific $\operatorname{IgE}$ and is one of the most common wheat allergens implicated in baker's asthma, ${ }^{5}$ anaphylaxis, and in some cases of WDEIA. ${ }^{29}$ It is present in raw and cooked wheat and appears to be heat resistant and lacks significant cross-reactivity to grass pollen allergens. ${ }^{29}$ Water insoluble $\omega-5$-gliadin (Tri a 19) has been identified as a major allergen in Finnish subjects with WDEIA. . $^{15,30,31}$

Tri a 37 is a plant defense protein and is highly expressed in wheat seeds. It is highly stable and resistant to heat and digestion. Therefore, this protein can act as a potent allergen and those who have $\operatorname{IgE}$ antibodies against Tri a 37 have a four fold increased risk of severe allergic symptoms upon wheat ingestion. ${ }^{32-34}$ Nonspecific lipid transfer protein (nsLTP or Tri a 14) has been shown to be an important allergen for IgE mediated food allergies (especially in Italian children), WDEIA and baker's asthma. ${ }^{29,35,36}$

Sanchez-Monge et $\mathrm{al}^{37}$ and Yamashita et $\mathrm{al}^{38}$ identified peroxidase, an IgE-binding protein of $36 \mathrm{kDa}$ from wheat flour. Approximately $60 \%$ of patients with baker's asthma displayed specific IgE to peroxidase. Thioredoxins are $12-14 \mathrm{kDa}$ storage proteins present in wheat seeds and have been recognized as a wheat allergen, Tri a 25 , able to induce baker's asthma. ${ }^{39-41}$ Serine proteinase inhibitor, a $9.9 \mathrm{kDa}$ protein, is mainly expressed in mature seeds and has been found to be an allergen important in 14\%-27\% of Spanish patients with baker's asthma. ${ }^{42,43}$ Thaumatinlike proteins are salt-soluble proteins that are part of pathogenesis-related proteins in the wheat flour and have a molecular weight from 21 to $26 \mathrm{kDa}$. They are allergenic

Table I Allergens in wheat flour

\begin{tabular}{|c|c|c|c|}
\hline Allergen name & $\begin{array}{l}\text { Allergen } \\
\text { abbreviation }\end{array}$ & $\begin{array}{l}\text { Molecular } \\
\text { weight (kDa) }\end{array}$ & Reference \\
\hline$\alpha$-purothionin & Tri a 37 & 37 & $32-34$ \\
\hline $\begin{array}{l}\alpha \text {-amylase/trypsin } \\
\text { inhibitor }\end{array}$ & $\begin{array}{l}\text { Tri a } 28 \text { and } \\
\text { Tri a } 29.01\end{array}$ & $12-16$ & 5,29 \\
\hline Peroxidase & Tri a Bd36 kd & 36 & 37,38 \\
\hline Thioredoxin & Tri a 25 & 25 & $39-41$ \\
\hline Lipid protein transfer & Tri a 14 & 14 & $29,35,36,128$ \\
\hline $\begin{array}{l}\text { Serine proteinase } \\
\text { inhibitor }\end{array}$ & Tri a 29 & 9.9 & 42,43 \\
\hline $\begin{array}{l}\text { Thaumatin-like } \\
\text { protein (TLP) }\end{array}$ & & $2 I-26$ & 44 \\
\hline Gliadin & $\omega-5$-gliadin & 65 & $30,31,45$ \\
\hline Thiol reductase & Tri a 27 & 27 & 128,129 \\
\hline I-cys-peroxiredoxin & Tri a 32 & & 128,130 \\
\hline $\begin{array}{l}\text { Serine protease like } \\
\text { inhibitor }\end{array}$ & Tri a 39 & & 128,130 \\
\hline
\end{tabular}


and have been found to be able to sensitize $30 \%-45 \%$ of Finnish patients with baker's asthma. ${ }^{44}$

Several of the major water/salt-insoluble wheat flour proteins (prolamins), including by $\alpha-, \beta-, \gamma-$, and $\omega$-gliadins; and low-molecular-weight (LMW) glutenin subunits appear to be able to bind to IgE and to be implicated in baker's asthma. For example, the $12 \%$ of patients with baker's asthma had IgE reactive $\alpha \beta$-gliadin (molecular weight of $20 \mathrm{kDa}$ ) and $33 \%$ showed sensitization to natural total gliadin. ${ }^{45}$

\section{Diagnosis}

The diagnosis of an IgE mediated wheat allergy is based on an accurate history that documents the symptoms specific of IgE mediated food allergy to wheat, WDEIA, or occupational respiratory allergies to wheat flour. ${ }^{12,15,18}$ When these symptoms occur within 1-3 hours of wheat exposure the allergy to wheat needs to be confirmed by measuring IgE specific to wheat by SPT or in the serum IgE (sIgE). The presence of specific sIgE to wheat without a clear history of symptoms after wheat exposure is not diagnostic as many people can be sensitive to wheat but can tolerate wheat exposure, especially in grass pollen sensitive individuals..$^{46,47}$ Indeed patients with grass pollen sensitivity carry IgE specific for cereal derived allergens and several studies have reported cross-reactivity between wheat flour and grass pollen due to common IgE epitopes in wheat flour and grass pollen proteins. ${ }^{46,47}$ Furthermore, a diagnosis based on wheat flour extract does not allow discrimination between patients suffering from a respiratory allergy and those suffering from a food allergy to wheat. Finally, the characteristic extractability properties of wheat grain proteins have significant implication for commercially available diagnostic products. For example, the wheat ImmunoCAP ${ }^{\circledR}$ contains a significantly higher amount of salt-soluble fraction, whereas the salt insoluble fraction is detected by glutenin and/or $\omega-5$ gliadin ImmunoCAP. ${ }^{5}$

The cutoff levels for specific sIgE for wheat which predict a true allergy to wheat, as well as the confirmatory gold standard challenges, vary depending on which disease needs to be diagnosed: IgE mediated food allergy to wheat, WDEIA, or baker's asthma.

In the last few years there has been significant advances in the description of many allergens that may cause respiratory and/or IgE mediated food allergies (Table 1). However, none have reached a high specificity and sensitivity to become a gold standard for the diagnosis of wheat allergy and therefore, the precise diagnosis still relies on specific clinical standardized challenges done under medical supervision. . $^{3,17}$

A food allergy to wheat manifests with a variety of symptoms that include urticaria/angioedema, asthma, allergic rhinitis, abdominal pain, vomiting, acute exacerbation of atopic dermatitis, and EIA, all of which may start within 2 hours after the first exposure to wheat. ${ }^{3-5}$ Once a food allergy to wheat is suspected, the diagnosis needs to be confirmed by demonstrating specific IgE against wheat. The cutoff levels of $\mathrm{IgE}$ that can predict whether the reaction is a true wheat allergy in $>90 \%$ of patients is not well established, with most studies showing that children even with high levels of $\operatorname{IgE}(>20$ $\mathrm{kU} / \mathrm{L}$ ) can tolerate certain foods when they undergo an oral food challenge (OFC) to wheat (Table 2)..$^{12,48-50}$ Similarly, IgE in serum cannot predict whether a child will become tolerant

Table 2 Sensitivity, specificity, positive predictive values (PPVs), and negative predictive values (NPVs) of SPT and serum IgE for the diagnosis of food allergy to wheat

\begin{tabular}{|c|c|c|c|c|c|}
\hline Cutoff levels & Population used in the study & Sensitivity (\%) & Specificity (\%) & PPV (\%) & NPV (\%) \\
\hline $\begin{array}{l}\text { Wheat serum lgE level } \\
>0.36 \mathrm{kU} / \mathrm{L}^{124}\end{array}$ & $\begin{array}{l}\text { Forty children with diagnosis confirmed with OFC } \\
\text { or DBPCFC to wheat }\end{array}$ & 95 & 67 & 72 & 93 \\
\hline Wheat serum $\lg E=10.1 \mathrm{kU} / \mathrm{L}^{125}$ & $\begin{array}{l}\text { One hundred seventy three children with confirmed } \\
\text { diagnosis of IgE mediated food allergy to wheat, } \\
\text { either by OFC or by recent history of anaphylaxis }\end{array}$ & 61 & 74 & 75 & 60 \\
\hline $\begin{array}{l}\text { Wheat serum } \lg E=26 \mathrm{kU} / \mathrm{L} \\
(90 \% \text { decision point })^{126}\end{array}$ & $\begin{array}{l}\text { Twenty three children with DBPCFC confirmed } \\
\text { diagnosis of IgE mediated food allergy to wheat }\end{array}$ & 61 & 92 & 74 & 87 \\
\hline $\begin{array}{l}\text { Wheat serum } \lg E=100 \mathrm{kU} / \mathrm{L} \\
(95 \% \text { decision point })^{126}\end{array}$ & $\begin{array}{l}\text { Twenty three children with DBPCFC confirmed } \\
\text { diagnosis of IgE mediated food allergy to wheat }\end{array}$ & 13 & 100 & 100 & 76 \\
\hline $\begin{array}{l}\text { Wheat SPT }(\text { wheat } \\
\text { diameter }=3 \mathrm{~mm})^{124}\end{array}$ & $\begin{array}{l}\text { Forty children with diagnosis confirmed with OFC } \\
\text { or DBPCFC to wheat }\end{array}$ & 89 & 71 & 74 & 88 \\
\hline $\begin{array}{l}\hat{\omega}-5 \text { gliadin serum } \lg E=0.41 \mathrm{kU} / \mathrm{L} \\
\lg \mathrm{E} \text { mediated food allergy }{ }^{125}\end{array}$ & $\begin{array}{l}\text { One hundred seventy three children with confirmed } \\
\text { diagnosis of IgE mediated food allergy to wheat, } \\
\text { either by OFC or by recent history of anaphylaxis }\end{array}$ & 72 & 79 & 81 & 69 \\
\hline $\begin{array}{l}\omega-5 \text { gliadin serum IgE =0.89 kU/L } \\
\text { for WDEIA }{ }^{127}\end{array}$ & $\begin{array}{l}\text { Fifty children and adults with confirmed diagnosis } \\
\text { of IgE mediated food allergy to wheat, either by } \\
\text { OFC or by recent history of anaphylaxis }\end{array}$ & 78 & 96 & $\mathrm{~N} / \mathrm{A}$ & $\mathrm{N} / \mathrm{A}$ \\
\hline
\end{tabular}

Abbreviations: IgE, immunolglobulin E; DBPCFC, double blind placebo controlled food challenge; OFC, oral food challenge; SPT, skin prick test; WDEIA, wheat-dependent, exercise-induced anaphylaxis; N/A, not available. 
after a period of avoidance or the severity of their reaction., ${ }^{3,51}$ Therefore, OFCs remain mandatory where there is a no clear history of IgE mediated reaction to wheat, even if IgE specific to wheat can be demonstrated. ${ }^{3,48,49}$ Most studies have found that wheat OFCs are generally safe, with a rate of failure $(30 \%-50 \%)$ and use of epinephrine $(10 \%-20 \%)$ similar to other foods (ie, milk, egg, and peanuts), but near fatal reactions can occur and therefore they should be performed by health care providers trained in taking care of patients who have anaphylaxis. ${ }^{3,4}$ The OFC will therefore be essential to rule out conditions that can mimic an IgE mediated food allergy (Table 3).

An accurate diagnosis of WDEIA is extremely important to avoid further severe reactions. However, a prolonged time

Table 3 Differential diagnosis of lgE mediated allergy to wheat

\begin{tabular}{|c|c|}
\hline \multicolumn{2}{|l|}{ Vasovagal reactions } \\
\hline Non-IgE mediated food allergy & $\begin{array}{l}\text { Food protein induced enterocolitis } \\
\text { considered in infancy } \\
\text { Celiac disease }\end{array}$ \\
\hline Flush syndrome & $\begin{array}{l}\text { Carcinoid } \\
\text { Postmenopausal } \\
\text { Chlorpropamide-alcohol } \\
\text { Autonomic epilepsy }\end{array}$ \\
\hline Restaurant syndromes & $\begin{array}{l}\text { Sodium glutamate } \\
\text { Sulfitis } \\
\text { Scombroid }\end{array}$ \\
\hline Non-anaphylactic shock & $\begin{array}{l}\text { Hemorrhagic } \\
\text { Cardiac } \\
\text { Endotoxic } \\
\text { Monoclonal gammopathy } \\
\text { (parossistica hyperpermeability) }\end{array}$ \\
\hline $\begin{array}{l}\text { Syndromes with excessive } \\
\text { endogenous production of } \\
\text { histamine }\end{array}$ & $\begin{array}{l}\text { Idiopathic urticaria } \\
\text { Idiopathic angioedema } \\
\text { Mastocytosis } \\
\text { Urticaria pigmentosa } \\
\text { Basophil leukemia } \\
\text { Promyelocytic acute leukemia acute } \\
\text { Hydatid cyst }\end{array}$ \\
\hline Nonorganic syndromes & $\begin{array}{l}\text { Panic attack } \\
\text { Munchausen } \\
\text { Vocal cord dysfunction } \\
\text { Hysteric bolus } \\
\text { Anorexia nervosa }\end{array}$ \\
\hline Miscellaneous & $\begin{array}{l}\text { Hereditary angioedema } \\
\text { Anaphylaxis due to progesterone } \\
\text { Urticaria vasculitis } \\
\text { Feocromocitoma } \\
\text { Hyper IgE syndrome } \\
\text { Neurologic diseases (seizures, } \\
\text { stroke) } \\
\text { Pseudo-anaphylaxis } \\
\text { Red man syndrome (Vancomycin) } \\
\text { Constipation } \\
\text { Irritable bowel syndrome }\end{array}$ \\
\hline
\end{tabular}

Abbreviation: $\lg \mathrm{E}$, immunolglobulin $\mathrm{E}$. lag (32-62 months) to diagnosis is very frequent due to the rarity of the disease and the lack of recognition from physicians. ${ }^{15}$ Indeed WDEIA is often mistaken for other more common diseases such as urticaria, EIA, or idiopathic anaphylaxis (Table 3). ${ }^{15}$ Given how the disease is, the diagnosis is extremely dependent on the clinician ability to suspect the disease based on an accurate clinical history. ${ }^{52}$ Clinical presentations of WDEIA include pruritus, urticaria, angioedema, flushing, shortness of breath, dysphagia, chest tightness, syncope, profuse sweating, headache, nausea, diarrhea, colicky abdominal pain, throat closing, and hoarseness that occurs while performing intense exercise following a meal which included wheat in the 4 hours preceding the onset of WDEIA. ${ }^{16}$ In patients with suspected WDEIA, SPT, or specific IgE to wheat, gluten and $\omega-5$ gliadin should be performed. ${ }^{15,30,31}$ In a questionable diagnosis, an OFC followed by a maximal exercise on a treadmill may be necessary to confirm the diagnosis. ${ }^{15}$ These are high risk procedures, however, as the amount of food given and the intensity of exercise required to induce a reaction cannot be well controlled, and severe anaphylactic reactions have been reported. ${ }^{15,54,55} \mathrm{~A}$ negative challenge does not rule out WDEIA because several cofactors may be missed in a controlled challenge environment (ie, the intensity of exercise, pollen exposure, concomitant ingestions of non-steroidal anti-inflammatory drugs or alcohol, and the presence of menses in females). ${ }^{15,54,55} \mathrm{~A}$ recent study has indeed shown that alcohol and non-steroidal antiinflammatory drugs are a significant risk factor for WDEIA, and can induce WDEIA even in the absence of exercise in a small subgroup of patients. ${ }^{55}$ Like for any anaphylactic episode, elevated serum tryptase levels have been reported in subjects with WDEIA following an acute episode and can be helpful in determining the diagnosis if measured within 6 hours of an acute reaction. ${ }^{16}$

As for every type of occupational disease, the diagnosis of baker's asthma or rhinitis needs to be confirmed by objective methods because the diagnosis has significant social and financial impact. ${ }^{17,18}$ The diagnosis of baker's asthma or allergic rhinitis is based on clinical history, the presence of specific IgE to wheat and, in selected individuals, a positive nasal or bronchial response to provocation. ${ }^{17,18}$ Any new onset of asthma or allergic rhinitis in a worker exposed to significant wheat allergen should raise suspicion of a respiratory allergy to wheat. A good occupational history, including not only the current job but also past jobs and exposure, is very important. ${ }^{18}$ The sensitivity of SPTs and allergen-specific sIgE can be $74 \%-100 \%$ for higher levels of specific wheat IgE. ${ }^{56}$ In one study with over a 100 patients with baker's asthma,${ }^{56}$ the minimum cutoff values with positive predictive 
value (PPV) of $100 \%$ were $2.32 \mathrm{kU} / \mathrm{L}$ for specific wheat IgE and $5.0 \mathrm{~mm}$ for wheat on SPT with wheat flour extracts. If a patient has no or low levels of specific IgE against wheat, challenges with flour may be important in patients with typical symptoms of baker's asthma or allergic rhinitis. ${ }^{56}$ Indeed, this disorder has been classically considered a form of allergic asthma mediated by IgE antibodies specific to cereal flour antigens, mainly wheat, ${ }^{9}$ but other cereals (ie, rye, barley, and rice), flours from different sources (ie, soybean, buckwheat, and lupine), additives and contaminants present in flours (ie, enzymes, egg proteins, storage mites, molds, and insects) are also capable of causing IgE-mediated occupational asthma. Exposure to endotoxins have been reported among agricultural and grain elevator workers and mimic IgE mediated occupational asthma. ${ }^{18}$ Finally, several other conditions such as non-wheat induced allergic asthma, chronic obstructive pulmonary disease, chronic eosinophilic bronchitis, heart insufficiency, non-wheat induced allergic rhinitis, and rhinitis medicamentosa may mimic the wheat induced respiratory occupational diseases. ${ }^{18}$ To confirm wheat is the trigger of occupational asthma, it is important to demonstrate the presence of wheat allergen in the dust to which the worker is exposed to, and to do appropriate standardized clinical challenges under medical supervision when necessary. ${ }^{18}$

Demonstration of exposure to wheat allergen flour as measured by methods such as inhibition enzyme immunoassay, enzyme-linked immunosorbent assay inhibition, or an anti-wheat IgG4 serum, is important because epidemiological studies have shown that work-related sensitization risk is negligible when exposure to $0.2 \mathrm{mg} / \mathrm{m}^{3}$ of wheat allergen or $0.5 \mathrm{mg} / \mathrm{m}^{3}$ of inhalable dust during a work shift, and it increases proportionally to the levels of the allergen and the length of exposure to it. ${ }^{57-59}$

The gold standard to confirm the diagnosis of a wheat induced occupational therapy remains the bronchial challenge test. This test is typically performed by nebulization of commercial aqueous flour solutions in increasing concentrations $(0.01,0.1,1,10$, and $100 \mathrm{mg} / \mathrm{mL}$ by tidal volume breathing for 10 minutes) or by inhaling wheat flour dust (commercially available or obtained from the workplace) filled in capsules via spinhaler (King Pharmaceutical, Tennessee, TN, USA). ${ }^{56,60}$ Lung function can be measured by spirometry or by pletismography. ${ }^{56,60}$ Baker's asthma is diagnosed if a bronchial provocation test induces at least a $20 \%$ decrease in forced expiratory volume in 1 second or a threefold increase in nonspecific bronchial hyperreactivity accompanied by an increase in sputum eosinophilia. ${ }^{17}$
Molecular diagnosis of specific wheat IgE will reduce the necessity to do oral and inhaled wheat challenges in the future (Table 1). ${ }^{61,62}$

\section{Management}

At the moment, management of IgE mediated wheat allergy is mainly based on avoidance both in food and inhaled wheat allergens.

Patients with a food allergy to wheat must be trained to identify relevant food allergens in the labels, and written instruction should be given to effectively eliminate wheat from their diet. In the USA since 2005, Food Allergen Labeling and Consumer Protection Act of 2004 has been enacted to help with reading labels to prevent the accidental exposure to foods for eight of the most common food allergens (milk, egg, peanuts, tree nuts, fish, shellfish, soy, and wheat). Similar legislation have been introduced in Japan, Europe, and Australia. ${ }^{2}$

In case of accidental exposure and anaphylactic reaction, epinephrine administration with a self-injector device is the lifesaving treatment. This comes in strengths of either 0.15 or $0.3 \mathrm{mg}$, and is injected into the vastus lateralis muscle (lateral thigh). Based on the most recent guidelines from the National Institutes of Health, $0.15 \mathrm{mg}$ autoinjector should be used in children weighing less than or equal to $25 \mathrm{~kg}$ (55 lbs), including healthy infants weighing less than $10 \mathrm{~kg}$. ${ }^{4}$ The dose may be repeated at intervals of at least 5 minutes if necessary. ${ }^{4}$ After self-injection of epinephrine the patient needs to be seen at an emergency room, even if epinephrine has been effective and symptoms are resolved, as the effects of epinephrine are short-lived (approximately 20 minutes) and the reaction may need further treatment. ${ }^{4}$ All other treatments such as antihistamines, glucocorticoids, and $\beta$-agonists, either alone or in combination, are to be considered ancillary in the treatment of anaphylaxis. ${ }^{4}$

One promising way for treatment of a food allergy is immunotherapy. Currently, there are three techniques being studied: oral immunotherapy (OIT), sublingual immunotherapy (SLIT), and epicutaneous immunotherapy (EPIT). ${ }^{64}$ OIT and SLIT are based on the principle of slowly increasing the amount of food ingested in order to avoid experiencing systemic reactions.$^{64}$ OIT is the immunotherapeutic treatment with the largest body of evidence, having a decade-long experience in clinical trials. In several clinical trials, OIT for milk, egg, and peanuts is associated with up to $90 \%$ of desensitization status in short-term trials and up to $30 \%$ in longer-term responses to therapy, when the food is no longer eaten everyday. For example, after an OIT protocol trial for 
peanuts, 25 out of 25 patients that completed the protocol ( $89 \%$ of the 28 initially enrolled patients) were able to tolerate $5,000 \mathrm{mg}$ of peanuts (equivalent to 20 peanuts), whereas the placebo treated patients could only consume a mean of $280 \mathrm{mg}$ of peanuts (range: $0-1,900 \mathrm{mg}$ ). ${ }^{65}$ Similar results have been reported after milk OIT trials. ${ }^{66}$ OIT desensitization rates for egg have been reported to be closer to $75 \% .{ }^{67} \mathrm{Such}$ desensitized status is maintained only in a fraction of patients if the food is not ingested daily, and has been reported to be $28 \%$ for egg. ${ }^{64,67}$ The most commonly used OIT protocols are typically divided into three phases requiring ingestion of allergen-specific flour in a food vehicle: 1) initial escalation with six to eight doses of allergen given during day 1 of OIT; 2) build-up dosing under medical observation in a protected environment until a target dose is reached (every 1-2 weeks over 6-12 months); and 3) daily home maintenance dosing (typically years). ${ }^{64}$ Wheat OIT has been trialed in both a small group of adults and children showing efficacy similar to the one described for milk and egg. ${ }^{64}$ There are also ongoing clinical OIT for wheat (NCT01980992, and NCT01755884, http://www.clinicaltrial.gov).

The major limitation of widespread use of OIT is due to safety concerns. ${ }^{64,68}$ All OIT protocols are associated with significant side effects with almost $10 \%$ of the treated patients experienced a systemic reaction requiring epinephrine, in addition only $60 \%-90 \%$ were able to achieve the final maximum dose and only $25 \%-50 \%$ maintained tolerance after $2-4$ years of therapy. Therefore, in the USA, it is still not recommended for regular clinical care at present. ${ }^{64} \mathrm{Up}$ to $10 \%$ of patients undergoing OIT develop eosinophilic esophagitis (EoE) when the particular food is reintroduced into the diet. ${ }^{64}$

With SLIT, patients take a dose of allergen as an extract which is placed under the tongue and then either spat out or swallowed. It has been successfully used for the treatment of asthma and allergic rhinitis. SLIT is not currently recommended for treatment of a food allergy, but it has been successful in causing desensitization to food allergens in clinical trials. ${ }^{64}$ The main advantage of SLIT is its favorable safety profile, and the main disadvantage is its lower efficacy compared to OIT. ${ }^{64}$ There has been no studies published so far on the use of SLIT for a wheat allergy.

EPIT uses a skin patch to deliver allergen to the patient. Preclinical trials for peanuts and milk have shown promising results. ${ }^{64,69,70}$ There is currently no wheat trail underway (http://www.clinicaltrials.gov) nor have any been published.

Management of WDEIA includes prompt treatment with epinephrine during an acute episode. ${ }^{15}$ To prevent WDEIA, the following strategies are recommended: 1) avoidance of exercise within 4-6 hours following wheat ingestion; 2) avoidance of exercising alone or in hot or humid weather, or during pollen allergy season; and 3) always carrying emergency medication. ${ }^{15}$ Once WDEIA occurs, it needs to be treated like a wheat induced anaphylaxis.

For baker's asthma and allergic rhinitis, like for many occupational related diseases, strict avoidance of occupational triggers, such as grain flours, remains the primary step in the management of the disease. ${ }^{18}$ However, as it has been done for other occupational agents such as latex, specific immunological treatments can become therapeutic options for baker's asthma. Standard subcutaneous immunotherapy has been reported to be effective in a few case series in Baker's asthma. ${ }^{71-73}$ However, the US Food and Drug Administration does not recommend injection therapy with food extracts. ${ }^{74}$ Also the use of omalizumab (anti-IgE monoclonal antibody) may represent a possible treatment in very selected cases of an occupational allergy, as well as an approach to reduce side effects of immunotherapy. ${ }^{75}$

\section{Non-IgE mediated food allergies Epidemiology}

Wheat can cause a non-IgE mediated allergic disorder by inducing a Th2 lymphocytic response largely independent from IgE-specific antibodies to wheat (non-IgE mediated inflammation). The vast majority of these responses are characterized by an eosinophilic infiltration in the gastrointestinal (GI) tract, and are called eosinophilic gastrointestinal diseases (EGIDs). ${ }^{76,77}$ Based on clinical characteristics, pathogenesis, and response to therapy, EGID can be divided into four principal groups: EoE, EG, eosinophilic gastroenteritis (EGE), and eosinophilic colitis (EC). ${ }^{76-78}$ Wheat has been found to be an important trigger of EoE and EG but not for EGE and EC and therefore, will not be reviewed in the current review. ${ }^{76-78}$

EoE is the most common type of EGID, with an incidence rate estimated to be similar to Crohn's disease (ie, $1 / 2,000)$ and it disproportionately affects Caucasian atopic males. ${ }^{79-82}$ EoE is characterized by pathological eosinophilia limited to the esophagus and driven, in the vast majority of cases, by an allergic response to foods ${ }^{83,84} \mathrm{EoE}$ is diagnosed when:

- there are signs of esophageal dysfunction (ie, symptoms of gastroesophageal reflux disease [GERD], vomiting, abdominal pain, dysphagia, and food impaction), and is not responsive to maximal proton pump inhibitor (PPI) therapy, and 
- an esophageal biopsy shows more than 15 eosinophil per high power field (eos/hpf). ${ }^{85}$

EG together with EGE and EC is part of a group of very rare, ill-defined diseases characterized by eosinophilia and limited to the GI (esophagus, stomach, duodenum, ileus, and colon) $)^{42,77,78}$ and a diagnosis of exclusion after other more common causes of eosinophilia have been ruled out (ie, parasitic infections, drug allergy, and inflammatory diseases associated to GI eosinophilia such as inflammatory bowel disease, Churg-Strauss syndrome, and lupus). ${ }^{77,78}$

EG is estimated to affect $6.3 / 100,000$ of the general population and is more prevalent in adults than in children. ${ }^{86}$ EG like EoE, is characterized by tissue eosinophilic inflammation, peripheral eosinophilia, coexisting allergic diseases (eg, allergic rhinitis and/or asthma), and sensitization to multiple food allergens. Also, EG, like EoE, is more prevalent in males. ${ }^{87-89}$

\section{Pathogenesis}

EoE is a food allergy driven atopic disease characterized by Th2 inflammation and limited to the esophagus. ${ }^{83,90-95}$ Esophageal epithelial cell dysfunction is likely to start the inflammatory process in genetically predisposed individuals. ${ }^{91,94-100}$

Several independent groups have demonstrated that Th2 cytokines like IL-13, IL-5, and IL-4 cause the inflammation, eosinophilia, and fibrotic changes observed in EoE. However, such Th2 cytokines appear to have redundant effects, as treatment strategies that target a single cytokine (ie, anti-IL-5 or anti-IL-13 antibodies) have not been able to completely control and treat EoE. ${ }^{101}$ Similarly eosinophils seem to be a marker of Th2 inflammation and not pathogenetic, as anti-IL5 effectively reduces eosinophil infiltration without abolishing EoE esophageal inflammation, fibrosis, and related clinical symptoms. ${ }^{101}$

Unlike in $\mathrm{IgE}$ mediated allergic reactions in EoE, the Th2 inflammation appears to be driven by a dysfunctional epithelium. More specifically, thymic stromal lymphopoietin produced by the esophageal epithelium in genetically predisposed individuals could be one of the major initial driver of the Th2 inflammation in EoE. ${ }^{52,93,95}$ Furthermore, the epithelial barrier dysfunction described in patients with $\mathrm{EoE}^{102}$ could be responsible for enhanced access of food allergens and consequently local sensitization to food allergens in the presence of Th2 inflammation, leading to a chronic food allergy driven inflammation.

Like in any other atopic disease, the vast majority of cases of EoE are triggered by allergens. Specifically in most children and adults, particular foods have been identified as the trigger of EoE Th2 inflammation with a largely non-IgE mediated mechanism..$^{53,83,103,104}$ Testing for a food allergy by SPT or specific sIgE has not been proven successful in definitive identification of causative foods in EoE, despite the efficacy of targeted food diets in the treatment of EoE. ${ }^{105}$ Limited clinical trials have also shown that anti-IgE therapy with omalizumab has no effect on esophageal eosinophilia. ${ }^{106}$ OIT is associated with the development of EoE in $2 \%-10 \%$ of desensitized patients. ${ }^{107,108}$

The most common food allergens responsible for EoE in both children and adults are milk and wheat. ${ }^{53,83,105,109}$ Spergel et al ${ }^{105}$ found that wheat was the definitive cause of EoE in $12 \%$ of children and therefore, it was the second most common causative food after milk. Gonsalves et al ${ }^{110}$ and Molina-Infante et $\mathrm{al}^{111}$ found that in adult patients wheat was the most common causative food as it was triggered $60 \%$ and $31 \%$ of the time, respectively. No specific allergen of wheat has been determined as a trigger of EoE. ${ }^{112}$ SPT and the measurement of sIgE for wheat have shown no utility in predicting which patients will respond to a wheat elimination diet. ${ }^{105,110,111}$

The inflammation present in EG, the patients clinical characteristics, and the response to treatment (ie, Th2 inflammation, male predominance, and response to diet and steroid treatment) are very similar to the one found in EoE, however, genome-wide transcript profiling has shown a distinct signature of EG compared to EoE with only $7 \%$ of EG patients having a transcriptome that overlapped with EoE patients. EG is therefore a different disease than EoE being more systemic and is associated with high levels of blood/GI eosinophilia and Th2 immunity. ${ }^{87} \mathrm{EG}$ have been shown to be triggered by foods (including wheat), however, data on the role of food allergens in EG pathogenesis are scarce, because the disease is quite rare. Ko et al demonstrated that $82 \%$ of children with EG had resolution after the implementation of an elimination diet that excluded either wheat alone or with other major allergens such as milk, soy, egg, peanuts, and nuts. ${ }^{88}$

\section{Diagnosis}

EoE is a clinicopathological diagnosis and is suspected if patients present symptoms of a dysfunctional, inflamed, and/or fibrotic esophagus. The typical EoE symptoms, such as dysphagia and food impaction, are due to esophageal fibrosis and are more frequent in older children and adults. Infants and young children tend to present more aspecific symptoms of esophageal dysmotility such as gagging, failure to progress in solid introduction and to thrive, and abdominal pain/vomiting and therefore their diagnosis may 
be missed for a long time. ${ }^{113-115}$ When suspected, EoE is diagnosed by finding at least 15 eos/hpf in one esophageal biopsy obtained with esophagogastroduodenoscopy (EGD). Symptoms and biopsy findings in EoE can be very similar to findings in GERD, but differs in that they are typically not responsive to a maximal dose of PPI, and therefore, the diagnostic EGD should be done after at least 8 weeks of the maximum PPI dose. ${ }^{113-116}$

The diagnosis of which food causes EoE is not so easy. An IgE measurement for specific foods, either via SPT or specific sIgE detection, has little sensitivity and specificity, especially for the two most common triggers of EoE, milk and wheat. ${ }^{105}$ Even if the association of SPT with atopy patch test increased the sensitivity and specificity of food allergy testing, ${ }^{83}$ an elimination diet followed after 8 weeks by an EGD remain the gold standard to evaluate the importance of a food allergen in EoE pathogenesis. Trials in which microarray allergens were used to guide the diet have been terminated as most patients failed the diet. ${ }^{63}$

Symptoms of EG are characterized by abdominal pain and bloating. Patients with a prominent gastric inflammation have nausea, vomiting, and early satiety. On the other hand, patients with prominent duodenal inflammation have malabsorption and protein losing enteropathy. Many patients can have both duodenal and gastric symptoms. If eosinophils involves the muscularis layer of the duodenum or stomach, there can be severe complications such as GI obstruction or GI perforation. ${ }^{89} \mathrm{EG}$ is diagnosed when clinical symptoms suggestive of EG are corroborated by a positive biopsy showing eosinophilic inflammation. Biopsies should be obtained from five-six sites per affected segment (eg, stomach and duodenum), and $30 \mathrm{eos} / \mathrm{hpf}$ in the stomach and $50 \mathrm{eos} / \mathrm{hpf}$ in the duodenum are generally considered diagnostic. ${ }^{89}$ Peripheral eosinophilia $\left(>300 \mathrm{eos} / \mathrm{mm}^{3}\right)$ is common, but rarely is it moderate to severe $\left(300-1,500 \mathrm{eos} / \mathrm{mm}^{3}\right) .{ }^{89}$ Food allergy testing such as for EoE, is not sensitive or specific enough to guide the diet.

\section{Treatment}

The current clinically-accepted EoE management is similar to other atopic diseases and is based on allergen avoidance and corticosteroid use. Future treatments will probably rely on the induction of antigen tolerance and specific biological treatments.

Steroid treatment for an $\operatorname{IgE}$ mediated food allergy is a very effective treatment of EoE. Oral steroids are an effective short term treatment but they cannot be used as a long term therapy because of well-known side effects. ${ }^{117}$ Swallowed or inhaled corticosteroids (ie, viscous budesonide and Flovent) are effective and well tolerated "topical" treatments. ${ }^{18,119}$

Particular foods are known to trigger EoE in adults and children. ${ }^{109}$ There are three accepted dietary approaches that can be used to treat EoE: 1) an elemental diet (effective in virtually all patients) that is based on the ingestion of only elemental formulas, 2) specific antigen avoidance based on allergy testing and/or diet history, and 3) empiric food elimination based on the most common food antigens (also known as six-food elimination diet in which milk, egg, wheat, soy, peanuts/tree nuts, and fish/shellfish are eliminated). ${ }^{85,120}$

It is very unlikely that OIT will work for EoE. Indeed one of the major side effects of OIT is the induction of EoE. ${ }^{64,107,108,121}$ Immunotherapeutic approaches that bypass the esophagus, such as EPIT, may be used in the future.

In both pediatric and adult patients with an EG diet (both elemental and six-food elimination diet), it has been reported to be effective in the majority of pediatric patients. ${ }^{88}$ However, diet alone is rarely an effective treatment as symptoms are severe and need steroids to quickly curb them. Therefore, most patients are treated initially with systemic steroids (0.5-1 mg/kg/day for 5-14 days) followed by a slow tapering off over several weeks ( $2-4$ weeks). Once remission is achieved, long term therapy can be done with diet or with the use of topical or oral steroids. Swallowed budesonide is well studied in EG and has low oral bioavailability. ${ }^{122}$ Entocort $^{\circledR}$ budesonide capsules (typically $9 \mathrm{mg}$ once daily) need to be opened to crush the contents into a powder, which then is dissolved in $15-30 \mathrm{~mL}$ of water and juice. ${ }^{122}$ Swallowed fluticasone has been used to decrease gastric eosinophils. ${ }^{123}$

\section{Conclusion}

Wheat can cause IgE mediated and non-IgE mediated allergic reactions. IgE mediated reactions can occur from either ingestion (food allergy) or inhalation (occupational allergy) of wheat. A food allergy is more commonly found in children than in adults and can be associated with severe reactions such as anaphylaxis and WDEIA. A food allergy diagnosis is based on detecting a combination of specific $\mathrm{IgE}$ to wheat via SPT or sIgE measurement and OFC in a person. Treatment for a food allergy at present is based on either avoidance of wheat altogether, or if ingested, then emergency lifesaving self-injectable epinephrine can be used. However, in the near future immunotherapy (OIT, SLIT, and EPIT) may represent a valid way to treat the disease. 
Respiratory IgE mediated wheat allergy can cause baker's asthma and rhinitis, a common occupational disease in bakers and workers with significant repetitive contact to wheat flour. Diagnosis is based on a combination of detection of specific IgE to wheat and inhalation wheat challenges. Treatment is based on avoidance. In the near future immunotherapy (OIT, SLIT, and EPIT) may represent a valid way to treat the disease.

Non-IgE mediated food allergies to wheat are mainly EoE and EG. EoE is an increasingly recognized food allergy that affects mainly Caucasian, atopic males. Wheat is one of the major triggers of the disease and diagnosis is based on the presence of at least 15 eos/hpf in one esophageal biopsy after 8 weeks of PPI treatment. Diagnosis of a food allergy is based on a food elimination diet followed by an EGD which shows a resolution of the disease. EG is a rare disease that is associated with severe symptoms which needs prompt treatment with oral steroids followed by an elimination diet in an attempt to maintain such remission. Measurement of specific IgE to wheat is not a valuable tool to decide if wheat triggers EG.

\section{Disclosure}

The author reports no conflicts of interest in this work.

\section{References}

1. Fasano A, Sapone A, Zevallos V, Schuppan D. Nonceliac gluten sensitivity. Gastroenterology. 2015;148(6):1195-1204.

2. Cianferoni A, Spergel JM. Food allergy: review, classification and diagnosis. Allergol Int. 2009;58(4):457-466.

3. Cianferoni A, Khullar K, Saltzman R, et al. Oral food challenge to wheat: a near-fatal anaphylaxis and review of 93 food challenges in children. World Allergy Organ J. 2013;6(1):14.

4. Cianferoni A, Muraro A. Food-induced anaphylaxis. Immunol Allergy Clin North Am. 2012;32(1):165-195.

5. Salcedo G, Quirce S, Diaz-Perales A. Wheat allergens associated with Baker's asthma. J Investig Allergol Clin Immunol. 2011;21(2):81-92.

6. Novembre E, Cianferoni A, Bernardini R, et al. Epidemiology of insect venom sensitivity in children and its correlation to clinical and atopic features. Clin Exp Allergy. 1998;28(7):834-838.

7. Poole JA, Barriga K, Leung DY, et al. Timing of initial exposure to cereal grains and the risk of wheat allergy. Pediatrics. 2006;117(6): 2175-2182.

8. Venter C, Pereira B, Grundy J, Clayton CB, Arshad SH, Dean T. Prevalence of sensitization reported and objectively assessed food hypersensitivity amongst six-year-old children: a population-based study. Pediatr Allergy Immunol. 2006;17(5):356-363.

9. Venter C, Pereira B, Grundy J, et al. Incidence of parentally reported and clinically diagnosed food hypersensitivity in the first year of life. J Allergy Clin Immunol. 2006;117(5):1118-1124.

10. Venter C, Pereira B, Voigt K, et al. Comparison of open and doubleblind placebo-controlled food challenges in diagnosis of food hypersensitivity amongst children. J Hum Nutr Diet. 2007;20(6): 565-579.

11. Venter C, Pereira B, Voigt K, et al. Prevalence and cumulative incidence of food hypersensitivity in the first 3 years of life. Allergy. 2008;63(3): 354-359.
12. Keet CA, Matsui EC, Dhillon G, Lenehan P, Paterakis M, Wood RA. The natural history of wheat allergy. Ann Allergy Asthma Immunol. 2009; 102(5):410-415.

13. Aihara Y, Kotoyori T, Takahashi Y, Osuna H, Ohnuma S, Ikezawa Z. The necessity for dual food intake to provoke food-dependent exercise-induced anaphylaxis (FEIAn): a case report of FEIAn with simultaneous intake of wheat and umeboshi. J Allergy Clin Immunol. 2001;107(6):1100-1105.

14. Pourpak Z, Ghojezadeh L, Mansouri M, Mozaffari H, Farhoudi A. Wheat anaphylaxis in children. Immunol Invest. 2007;36(2):175-182.

15. Scherf KA, Brockow K, Biedermann T, Koehler P, Wieser H. Wheatdependent exercise-induced anaphylaxis. Clin Exp Allergy. Epub 2015 Sep 18 .

16. Du Toit G. Food-dependent exercise-induced anaphylaxis in childhood. Pediatr Allergy Immunol. 2007;18(5):455-463.

17. Wiszniewska M, Nowakowska-Swirta E, Palczynski C, Walusiak-Skorupa J. Diagnosing of bakers' respiratory allergy: is specific inhalation challenge test essential? Allergy Asthma Proc. 2011;32(2):111-118.

18. Quirce S, Diaz-Perales A. Diagnosis and management of grain-induced asthma. Allergy Asthma Immunol Res. 2013;5(6):348-356.

19. Sampson HA. Food allergy. Part 1: immunopathogenesis and clinical disorders. J Allergy Clin Immunol. 1999;103(5 Pt 1):717-728.

20. Lee LA, Burks AW. Food allergies: prevalence, molecular characterization, and treatment/prevention strategies. Annu Rev Nutr. 2006;26: 539-565.

21. Chehade M, Mayer L. Oral tolerance and its relation to food hypersensitivities. J Allergy Clin Immunol. 2005;115(1):3-12.

22. Heyman M. Symposium on 'dietary influences on mucosal immunity'. How dietary antigens access the mucosal immune system. Proc Nutr Soc. 2001;60(4):419-426.

23. Iwasaki A. Mucosal dendritic cells. Annu Rev Immunol. 2007;25: 381-418.

24. Dahan S, Roth-Walter F, Arnaboldi P, Agarwal S, Mayer L. Epithelia: lymphocyte interactions in the gut. Immunol Rev. 2007;215:243-253.

25. Mowat AM. Anatomical basis of tolerance and immunity to intestinal antigens. Nat Rev Immunol. 2003;3(4):331-341.

26. Lack G. Epidemiologic risks for food allergy. J Allergy Clin Immunol. 2008;121(6):1331-1336.

27. Romagnani P, Annunziato F, Piccinni MP, Maggi E, Romagnani S. Th1/ Th2 cells, their associated molecules and role in pathophysiology. Eur Cytokine Netw. 2000;11(3):510-511.

28. Radauer C, Breiteneder H. Evolutionary biology of plant food allergens. J Allergy Clin Immunol. 2007;120(3):518-525.

29. Pastorello EA, Farioli L, Conti A, et al. Wheat IgE-mediated food allergy in European patients: alpha-amylase inhibitors, lipid transfer proteins and low-molecular-weight glutenins. Allergenic molecules recognized by double-blind, placebo-controlled food challenge. Int Arch Allergy Immunol. 2007;144(1):10-22.

30. Palosuo K, Alenius H, Varjonen E, et al. A novel wheat gliadin as a cause of exercise-induced anaphylaxis. J Allergy Clin Immunol. 1999;103(5 Pt 1): 912-917.

31. Morita E, Matsuo H, Mihara S, Morimoto K, Savage AW, Tatham AS. Fast omega-gliadin is a major allergen in wheat-dependent exerciseinduced anaphylaxis. J Dermatol Sci. 2003;33(2):99-104.

32. Pahr S, Selb R, Weber M, et al. Biochemical, biophysical and IgEepitope characterization of the wheat food allergen, Tri a 37. PloS one. 2014;9(11):e111483.

33. Pahr S, Constantin C, Papadopoulos NG, et al. alpha-Purothionin, a new wheat allergen associated with severe allergy. J Allergy Clin Immunol. 2013;132(4):1000-1003.

34. Pahr S, Constantin C, Mari A, et al. Molecular characterization of wheat allergens specifically recognized by patients suffering from wheatinduced respiratory allergy. Clin Exp Allergy. 2012;42(4):597-609.

35. Palacin A, Quirce S, Armentia A, et al. Wheat lipid transfer protein is a major allergen associated with baker's asthma. J Allergy Clin Immunol. 2007;120(5):1132-1138. 
36. Pastorello EA, Farioli L, Stafylaraki C, et al. Wheat-dependent exercise-induced anaphylaxis caused by a lipid transfer protein and not by omega-5 gliadin. Ann Allergy Asthma Immunol. 2014;112(4): 386-387.

37. Sánchez-Monge R, García-Casado G, López-Otín C, Armentia A, Salcedo G. Wheat flour peroxidase is a prominent allergen associated with baker's asthma. Clin Exp Allergy. 1997;27(10): $1130-1137$.

38. Yamashita H, Nanba Y, Onishi M, Kimoto M, Hiemori M, Tsuji H. Identification of a wheat allergen, Tri a $\mathrm{Bd} 36 \mathrm{~K}$, as a peroxidase. $\mathrm{Biosci}$ Biotechnol Biochem. 2002;66(11):2487-2490.

39. Kobrehel K, Wong JH, Balogh A, Kiss F, Yee BC, Buchanan BB. Specific reduction of wheat storage proteins by thioredoxin h. Plant Physiol. 1992;99(3):919-924.

40. Weichel M, Glaser AG, Ballmer-Weber BK, Schmid-Grendelmeier P, Crameri R. Wheat and maize thioredoxins: a novel cross-reactive cereal allergen family related to baker's asthma. J Allergy Clin Immunol. 2006;117(3):676-681.

41. Weichel M, Vergoossen NJ, Bonomi S, et al. Screening the allergenic repertoires of wheat and maize with sera from double-blind, placebo-controlled food challenge positive patients. Allergy. 2006;61(1):128-135.

42. Constantin C, Quirce S, Grote M, et al. Molecular and immunological characterization of a wheat serine proteinase inhibitor as a novel allergen in baker's asthma. J Immunol. 2008;180(11):7451-7460.

43. Constantin C, Quirce S, Poorafshar M, et al. Micro-arrayed wheat seed and grass pollen allergens for component-resolved diagnosis. Allergy. 2009;64(7):1030-1037.

44. Lehto M, Airaksinen L, Puustinen A, et al. Thaumatin-like protein and baker's respiratory allergy. Ann Allergy Asthma Immunol. 2010; 104(2):139-146.

45. Bittner C, Grassau B, Frenzel K, Baur X. Identification of wheat gliadins as an allergen family related to baker's asthma. J Allergy Clin Immunol. 2008;121(3):744-749.

46. Sander I, Raulf-Heimsoth M, Duser M, Flagge A, Czuppon AB, Baur X. Differentiation between cosensitization and cross-reactivity in wheat flour and grass pollen-sensitized subjects. Int Arch Allergy Immunol. 1997;112(4):378-385.

47. Jones SM, Magnolfi CF, Cooke SK, Sampson HA. Immunologic cross-reactivity among cereal grains and grasses in children with food hypersensitivity. J Allergy Clin Immunol. 1995;96(3):341-351.

48. Niggemann B, Sielaff B, Beyer K, Binder C, Wahn U. Outcome of double-blind, placebo-controlled food challenge tests in 107 children with atopic dermatitis. Clin Exp Allergy. 1999;29(1):91-96.

49. Niggemann B, Rolinck-Werninghaus C, Mehl A, Binder C, Ziegert M, Beyer K. Controlled oral food challenges in children - when indicated, when superfluous? Allergy. 2005;60(7):865-870.

50. Perry TT, Matsui EC, Conover-Walker MK, Wood RA. Risk of oral food challenges. J Allergy Clin Immunol. 2004;114(5):1164-1168.

51. Reibel S, Rohr C, Ziegert M, Sommerfeld C, Wahn U, Niggemann B What safety measures need to be taken in oral food challenges in children? Allergy. 2000;55(10):940-944.

52. Siracusa MC, Saenz SA, Hill DA, et al. TSLP promotes interleukin-3independent basophil haematopoiesis and type 2 inflammation. Nature. 2011;477(7363):229-233.

53. Gonsalves N. Food allergies and eosinophilic gastrointestinal illness. Gastroenterol Clin North Am. 2007;36(1):75-91, vi.

54. Fujita H, Osuna H, Kanbara T, Inomata N, Ikezawa Z. [Wheat anaphylaxis enhanced by administration of acetylsalicylic acid or by exercise] Arerugi. 2005;54(10):1203-1207. Japanese.

55. Brockow K, Kneissl D, Valentini L, et al. Using a gluten oral food challenge protocol to improve diagnosis of wheat-dependent exercise-induced anaphylaxis. J Allergy Clin Immunol. 2015;135(4): 977-984

56. van Kampen V, Rabstein S, Sander I, et al. Prediction of challenge test results by flour-specific IgE and skin prick test in symptomatic bakers. Allergy. 2008;63(7):897-902.
57. Houba R, Heederik D, Doekes G. Wheat sensitization and workrelated symptoms in the baking industry are preventable. An epidemiologic study. Am J Respir Crit Care Med. 1998;158(5 Pt 1): 1499-1503.

58. Houba R, Van Run P, Heederik D, Doekes G. Wheat antigen exposure assessment for epidemiological studies in bakeries using personal dust sampling and inhibition ELISA. Clin Exp Allergy. 1996;26(2):154-163.

59. Meijster T, Tielemans E, de Pater N, Heederik D. Modelling exposure in flour processing sectors in the Netherlands: a baseline measurement in the context of an intervention program. Ann Occup Hyg. 2007;51(3):293-304.

60. Merget R, Heger M, Globisch A, et al. Quantitative bronchial challenge tests with wheat flour dust administered by spinhaler: comparison with aqueous wheat flour extract inhalation. J Allergy Clin Immunol. 1997; 100(2):199-207.

61. Sander I, Rihs HP, Doekes G, et al. Component-resolved diagnosis of baker's allergy based on specific IgE to recombinant wheat flour proteins. J Allergy Clin Immunol. 2015;135(6):1529-1537.

62. Olivieri M, Biscardo CA, Palazzo P, et al. Wheat IgE profiling and wheat IgE levels in bakers with allergic occupational phenotypes. Occup Environ Med. 2013;70(9):617-622.

63. van Rhijn BD, Vlieg-Boerstra BJ, Versteeg SA, et al. Evaluation of allergen-microarray-guided dietary intervention as treatment of eosinophilic esophagitis. J Allergy Clin Immunol. 2015;136(4): 1095-1097.

64. Jones SM, Burks AW, Dupont C. State of the art on food allergen immunotherapy: oral, sublingual, and epicutaneous. JAllergy Clin Immunol. 2014;133(2):318-323

65. Varshney P, Jones SM, Scurlock AM, et al. A randomized controlled study of peanut oral immunotherapy: clinical desensitization and modulation of the allergic response. J Allergy Clin Immunol. 2011; 127(3):654-660.

66. Skripak JM, Nash SD, Rowley H, et al. A randomized, double-blind, placebo-controlled study of milk oral immunotherapy for cow's milk allergy. J Allergy Clin Immunol. 2008;122(6):1154-1160.

67. Burks AW, Jones SM, Wood RA, et al. Oral immunotherapy for treatment of egg allergy in children. $N$ Engl J Med. 2012;367(3): $233-243$.

68. Thyagarajan A, Varshney P, Jones SM, et al. Peanut oral immunotherapy (OIT) is not ready for clinical use. J Allergy Clin Immunol. 2010;126(1):31-32.

69. Kalach N, Soulaines P, de Boissieu D, Dupont C. A pilot study of the usefulness and safety of a ready-to-use atopy patch test (Diallertest) versus a comparator (Finn Chamber) during cow's milk allergy in children. J Allergy Clin Immunol. 2005;116(6): 1321-1326.

70. Dupont C, Kalach N, Soulaines P, Legoue-Morillon S, Piloquet H, Benhamou PH. Cow's milk epicutaneous immunotherapy in children: a pilot trial of safety, acceptability, and impact on allergic reactivity. J Allergy Clin Immunol. 2010;125(5):1165-1167.

71. Crivellaro M, Senna G, Marcer G, Passalacqua G. Immunological treatments for occupational allergy. Int J Immunopathol Pharmacol. 2013;26(3):579-584.

72. Armentia A, Martin-Santos JM, Quintero A, et al. Bakers' asthma: prevalence and evaluation of immunotherapy with a wheat flour extract. Ann Allergy. 1990;65(4):265-272.

73. Cirla AM, Lorenzini RA, Cirla PE. Recupero professionale di panificatiori allergici mediante vaccino verso farina di frumento [Specific immunotherapy and relocation in occupational allergic bakers]. Giornale italiano di medicina del lavoro ed ergonomia. 2007;29(3 Suppl):443-445. Italian.

74. Armentia A, Arranz M, Martin JM, et al. Evaluation of immune complexes after immunotherapy with wheat flour in bakers' asthma. Ann Allergy. 1992;69(5):441-444.

75. Olivieri M, Biscardo CA, Turri S, Perbellini L. Omalizumab in persistent severe bakers' asthma. Allergy. 2008;63(6):790-791. 
76. DeBrosse CW, Rothenberg ME. Allergy and eosinophil-associated gastrointestinal disorders (EGID). Curr Opin Immunol. 2008; 20(6):703-708.

77. Furuta GT, Forbes D, Boey C, et al. Eosinophilic gastrointestinal diseases (EGIDs). J Pediatr Gastroenterol Nutr. 2008;47(2): 234-238.

78. Straumann A. Idiopathic eosinophilic gastrointestinal diseases in adults. Best Pract Res Clin Gastroenterol. 2008;22(3):481-496.

79. Straumann A, Simon HU. Eosinophilic esophagitis: escalating epidemiology? J Allergy Clin Immunol. 2005;115(2):418-419.

80. Cherian S, Smith NM, Forbes DA. Rapidly increasing prevalence of eosinophilic oesophagitis in Western Australia. Arch Dis Child. 2006;91(12):1000-1004.

81. van Rhijn BD, Verheij J, Smout AJ, Bredenoord AJ. Rapidly increasing incidence of eosinophilic esophagitis in a large cohort. Neurogastroenterol Motil. 2013;25(1):47-52.

82. Hruz P, Straumann A, Bussmann C, et al. Escalating incidence of eosinophilic esophagitis: a 20-year prospective, population-based study in Olten County, Switzerland. J Allergy Clin Immunol. 2011; 128(6):1349-1350.

83. Spergel JM, Brown-Whitehorn TF, Beausoleil JL, et al. 14 years of eosinophilic esophagitis: clinical features and prognosis. $J$ Pediatr Gastroenterol Nutr. 2009;48(1):30-36.

84. Straumann A. Eosinophilic esophagitis: a bulk of mysteries. Dig Dis. 2013;31(1):6-9.

85. Liacouras CA, Furuta GT, Hirano I, et al. Eosinophilic esophagitis: updated consensus recommendations for children and adults. JAllergy Clin Immunol. 2011;128(1):3-20.

86. Jensen ET, Martin CF, Kappelman MD, Dellon ES. Prevalence of Eosinophilic Gastritis, Gastroenteritis, and Colitis: Estimates From a National Administrative Database. J Pediatr Gastroenterol Nutr. Epub 2015 May 20.

87. Caldwell JM, Collins MH, Stucke EM, et al. Histologic eosinophilic gastritis is a systemic disorder associated with blood and extragastric eosinophilia, TH2 immunity, and a unique gastric transcriptome. J Allergy Clin Immunol. 2014;134(5):1114-1124.

88. Ko HM, Morotti RA, Yershov O, Chehade M. Eosinophilic gastritis in children: clinicopathological correlation, disease course, and response to therapy. Am J Gastroenterol. 2014;109(8):1277-1285.

89. Prussin C. Eosinophilic gastroenteritis and related eosinophilic disorders. Gastroenterol Clin North Am. 2014;43(2):317-327.

90. Blanchard C, Mingler MK, Vicario M, et al. IL-13 involvement in eosinophilic esophagitis: transcriptome analysis and reversibility with glucocorticoids. J Allergy Clin Immunol. 2007;120(6):1292-1300.

91. Blanchard C, Wang N, Stringer KF, et al. Eotaxin-3 and a uniquely conserved gene-expression profile in eosinophilic esophagitis. $J$ Clin Invest. 2006;116(2):536-547.

92. Jyonouchi S, Smith CL, Saretta F, et al. Invariant natural killer $\mathrm{T}$ cells in children with eosinophilic esophagitis. Clin Exp Allergy. 2014;44(1):58-68

93. Noti M, Wojno ED, Kim BS, et al. Thymic stromal lymphopoietinelicited basophil responses promote eosinophilic esophagitis. Nat Med. 2013;19(8):1005-1013.

94. Sherrill JD, Gao PS, Stucke EM, et al. Variants of thymic stromal lymphopoietin and its receptor associate with eosinophilic esophagitis. $J$ Allergy Clin Immunol. 2010;126(1):160-165.

95. Rothenberg ME, Spergel JM, Sherrill JD, et al. Common variants at 5 q22 associate with pediatric eosinophilic esophagitis. Nat Genet. 2010;42(4):289-291.

96. Kottyan LC, Davis BP, Sherrill JD, et al. Genome-wide association analysis of eosinophilic esophagitis provides insight into the tissue specificity of this allergic disease. Nat Genet. 2014;46(8):895-900.

97. Noel RJ, Putnam PE, Rothenberg ME. Eosinophilic esophagitis. N Engl J Med. 2004;351(9):940-941.

98. Sherrill JD, Rothenberg ME. Genetic and epigenetic underpinnings of eosinophilic esophagitis. Gastroenterol Clin North Am. 2014; 43(2):269-280.
99. Franciosi JP, Tam V, Liacouras CA, Spergel JM. A case-control study of sociodemographic and geographic characteristics of 335 children with eosinophilic esophagitis. Clin Gastroenterol Hepatol. 2009;7(4):415-419.

100. Sleiman PM, Wang ML, Cianferoni A, et al. GWAS identifies four novel eosinophilic esophagitis loci. Nat Commun. 2014;5:5593.

101. Spergel JM, Rothenberg ME, Collins MH, et al. Reslizumab in children and adolescents with eosinophilic esophagitis: results of a doubleblind, randomized, placebo-controlled trial. J Allergy Clin Immunol. 2012;129(2):456-463.

102. Sherrill JD, Kc K, Wu D, et al. Desmoglein-1 regulates esophageal epithelial barrier function and immune responses in eosinophilic esophagitis. Mucosal immunology. 2014;7(3):718-729.

103. Kelly KJ, Lazenby AJ, Rowe PC, Yardley JH, Perman JA, Sampson HA. Eosinophilic esophagitis attributed to gastroesophageal reflux: improvement with an amino acid-based formula. Gastroenterology. 1995;109(5):1503-1512.

104. Kagalwalla AF, Sentongo TA, Ritz S, et al. Effect of six-food elimination diet on clinical and histologic outcomes in eosinophilic esophagitis. Clin Gastroenterol Hepatol. 2006;4(9): 1097-1102.

105. Spergel JM, Brown-Whitehorn TF, Cianferoni A, et al. Identification of causative foods in children with eosinophilic esophagitis treated with an elimination diet. J Allergy Clin Immunol. 2012;130(2): 461-467.

106. Clayton F, Fang JC, Gleich GJ, et al. Eosinophilic esophagitis in adults is associated with IgG4 and not mediated by IgE. Gastroenterology. 2014;147(3):602-609.

107. Lucendo AJ, Arias A, Tenias JM. Relation between eosinophilic esophagitis and oral immunotherapy for food allergy: a systematic review with meta-analysis. Ann Allergy Asthma Immunol. 2014; 113(6):624-629.

108. Maggadottir SM, Hill DA, Ruymann K, et al. Resolution of acute IgE-mediated allergy with development of eosinophilic esophagitis triggered by the same food. J Allergy Clin Immunol. 2014; 133(5):1487-1489.

109. Spergel JM. Eosinophilic esophagitis in adults and children: evidence for a food allergy component in many patients. Curr Opin Allergy Clin Immunol. 2007;7(3):274-278.

110. Gonsalves N, Yang GY, Doerfler B, Ritz S, Ditto AM, Hirano I. Elimination diet effectively treats eosinophilic esophagitis in adults; food reintroduction identifies causative factors. Gastroenterology. 2012;142(7):1451-1459.

111. Molina-Infante J, Arias A, Barrio J, Rodriguez-Sanchez J, Sanchez-Cazalilla M, Lucendo AJ. Four-food group elimination diet for adult eosinophilic esophagitis: A prospective multicenter study. J Allergy Clin Immunol. 2014;134(5):1093-1099.

112. Erwin EA, Tripathi A, Ogbogu PU, et al. IgE Antibody Detection and Component Analysis in Patients with Eosinophilic Esophagitis. J Allergy Clin Immunol Pract. Epub 2015 Jun 19.

113. Furuta GT, Liacouras CA, Collins MH, et al. Eosinophilic esophagitis in children and adults: a systematic review and consensus recommendations for diagnosis and treatment. Gastroenterology. 2007;133(4):1342-1363.

114. Menard-Katcher P, Marks KL, Liacouras CA, Spergel JM, Yang YX, Falk GW. The natural history of eosinophilic oesophagitis in the transition from childhood to adulthood. Aliment Pharmacol Ther. 2013;37(1):114-121.

115. Merves J, Muir A, Modayur Chandramouleeswaran P, Cianferoni A, Wang ML, Spergel JM. Eosinophilic esophagitis. Ann Allergy Asthma Immunol. 2014;112(5):397-403.

116. Liacouras CA, Spergel J, Gober LM. Eosinophilic esophagitis: clinical presentation in children. Gastroenterol Clin North Am. 2014;43(2):219-229.

117. Liacouras CA, Spergel JM, Ruchelli E, et al. Eosinophilic esophagitis: a 10-year experience in 381 children. Clin Gastroenterol Hepatol. 2005;3(12):1198-1206. 
118. Aceves SS, Bastian JF, Newbury RO, Dohil R. Oral viscous budesonide: a potential new therapy for eosinophilic esophagitis in children. $\mathrm{Am}$ J Gastroenterol. 2007;102(10):2271-2279.

119. Butz BK, Wen T, Gleich GJ, et al. Efficacy, dose reduction, and resistance to high-dose fluticasone in patients with eosinophilic esophagitis. Gastroenterology. 2014;147(2):324-333.

120. Greenhawt M, Aceves SS, Spergel JM, Rothenberg ME. The management of eosinophilic esophagitis. J Allergy Clin Immunol Pract 2013;1(4):332-340.

121. Sanchez-GarciaS, RodriguezDel Rio P,Escudero C,Martinez-GomezMJ, Ibanez MD. Possible eosinophilic esophagitis induced by milk oral immunotherapy. J Allergy Clin Immunol. 2012;129(4):1155-1157.

122. Tan AC, Kruimel JW, Naber TH. Eosinophilic gastroenteritis treated with non-enteric-coated budesonide tablets. Eur $J$ Gastroenterol Hepatol. 2001;13(4):425-427.

123. Ammoury RF, Rosenman MB, Roettcher D, Gupta SK. Incidental gastric eosinophils in patients with eosinophilic esophagitis: do they matter? J Pediatr Gastroenterol Nutr. 2010;51(6):723-726.
124. Palosuo K, Varjonen E, Kekki OM, et al. Wheat omega-5 gliadin is a major allergen in children with immediate allergy to ingested wheat. J Allergy Clin Immunol. 2001;108(4):634-638.

125. Ebisawa M, Shibata R, Sato S, Borres MP, Ito K. Clinical utility of IgE antibodies to omega-5 gliadin in the diagnosis of wheat allergy: a pediatric multicenter challenge study. Int Arch Allergy Immunol. 2012;158(1):71-76.

126. Sampson HA. Utility of food-specific IgE concentrations in predicting symptomatic food allergy. J Allergy Clin Immunol. 2001;107(5) 891-896.

127. Matsuo H, Dahlstrom J, Tanaka A, et al. Sensitivity and specificity of recombinant omega-5 gliadin-specific $\operatorname{IgE}$ measurement for the diagnosis of wheat-dependent exercise-induced anaphylaxis. Allergy. 2008;63(2):233-236

\section{Publish your work in this journal}

The Journal of Asthma and Allergy is an international, peer-reviewed open-access journal publishing original research, reports, editorials and commentaries on the following topics: Asthma; Pulmonary physiology; Asthma related clinical health; Clinical immunology and the immunological basis of disease; Pharmacological interventions and

\section{Dovepress}

new therapies. Issues of patient safety and quality of care will also be considered. The manuscript management system is completely online and includes a very quick and fair peer-review system, which is all easy to use. Visit http://www.dovepress.com/testimonials.php to read real quotes from published authors.

Submit your manuscript here: http://www.dovepress.com/journal-of-asthma-and-allergy-journal 